(c) American Dairy Science Association, 2007.

\title{
Gait Pattern of Heifers Before and After Claw Trimming: A High-Speed Cinematographic Study on a Treadmill
}

\author{
S. W. Meyer, ${ }^{*}$ M. A. Weishaupt, $†$ and K. A. Nuss ${ }^{\star 1}$ \\ *Department of Farm Animals, and \\ †Equine Clinic, Vetsuisse-Faculty, Winterthurerstrasse 260, CH-8057 Zurich, Switzerland
}

\begin{abstract}
The manner in which the claws contacted the ground at the walk was evaluated in 18 healthy heifers. The animals were filmed before and after claw trimming while walking on a treadmill using high-speed cinematography (500 frames/s). For each limb, 4 consecutive steps were recorded from a side and a frontal plane. The objectives of the study were to evaluate 1) the order of claw contact with the treadmill surface, 2) the initial claw contact area, and 3 ) the effect of trimming on claw contact patterns. The heifers placed their front feet on the ground in a plane sagittal to the shoulders, whereas the hind feet were advanced more toward the median plane. Before trimming, the lateral claws contacted the ground before the medial in $83 \%$ of front and $100 \%$ of hind limbs. Trimming changed the percentage to $92 \%$ in the front and to $97 \%$ in the hind limbs. The percentage with which the heel of the lateral claws became the region of initial contact with the ground increased from 47 to $64 \%$ in the front feet and from 50 to $78 \%$ in the hind feet. In the medial claws of the forelimbs, claw trimming shifted the region of initial contact from the toe to the abaxial wall and heel. In the hind limbs, the main region of initial contact of the medial claws became the abaxial wall. Weight bearing by the medial claw became visibly apparent only during the midstance, propulsion, and push-off phases. "Heel first" contact of the lateral claws in the front and hind limbs may be the normal gait pattern in cattle. On hard surfaces, this pattern may lead to overload and predispose to disease, especially in the hind limbs.
\end{abstract}

Key words: dairy cattle, lameness, claw, kinematics

\section{INTRODUCTION}

In cattle, sole ulcers usually occur on the lateral claw of the hind limbs. Chronic laminitis preferentially affects the lateral claws of the hind limbs (Smits et al.,

Received March 31, 2006.

Accepted September 13, 2006.

${ }^{1}$ Corresponding author: knuss@vetclinics.unizh.ch
1992; Nuss et al., 1996). In the forelimbs, sole ulcers are rare but when they occur, they are more common in the medial claw (Collick et al., 1989). The reasons for the predisposition of the different claws to certain disorders is not completely understood, although uneven weight distribution while standing or walking on hard flooring is thought to play a role (van der Tol et al., 2003; Huth et al., 2004). Measurements of ground reaction forces (GRF) showed that the lateral claws of the hind limb of cows received markedly higher average and maximum vertical pressures than the medial claws (Phillips et al., 2000; van der Tol et al., 2002; Kehler and Gerwing, 2004). In the forelimb, the weight distribution between the lateral and medial claws was almost equal in standing and walking cows (van der Tol et al., 2003). In calves and heifers, measurements showed greater weight bearing by the medial claw of the hind limb than the lateral claw while standing (Alsleben et al., 2003).

Functional trimming according to Toussaint Raven (1989) should promote natural weight bearing by increasing the contact area of the claws and by improving the balance between the medial and the lateral claw. However, only slight improvement was achieved after claw trimming when using pressure distribution measurements (van der Tol et al., 2004; Carvalho et al., 2005), and improvement was only transient (Kehler and Gerwing, 2004).

Treadmills have been used for gait evaluation in horses. The gait on a treadmill differs from that on other surfaces. The relative stance duration is slightly longer and the displacement of the withers as well as the maximal hoof heights were decreased on a treadmill compared with rubber ground (Buchner et al., 1994). However, on concrete, stride duration was shortened and the vertical displacement of the withers was even more decreased. The differences in kinematics did not disqualify the treadmill as an instrument of locomotion research (van Ingen-Schenau, 1980; Buchner et al., 1994). Trotting on the rubber belt of a treadmill was comparable to trotting on a rubber surface (Buchner et al., 1994). Concrete floors did not provide enough friction to allow unrestrained locomotion in cattle and contact pressures were very high compared with rubber flooring (van der Tol et al., 2004). In horses trotted by 
hand over a pressure measurement system, the preferred way of landing was lateral, asymmetrical landing in both front and hind feet (van Heel et al., 2004). These horses showed a fixed hoof-unrollment pattern, and hoof trimming did not have much influence on the way of landing. Lateral landing was regarded as the physiological standard in these horses.

According to Leach (1993), the stride is a full cycle of motion of a limb, which may be divided into different phases, beginning arbitrarily at any easily identifiable point, and is completed when the leg has returned to this initial position. The stance phase begins with heelfirst, flat-foot, or toe-first placement and ends with either heel-off or toe-off (Leach, 1993). Midstance has been defined as the time when the metacarpus is in the vertical position in the front limb stance phase and when the hip joint is vertical to the hoof in the hind limbs. The stance phase can be further divided into heel strike, maximum braking, midstance, maximum propulsion, and push off (Leach, 1993; van der Tol et al., 2003).

The detailed events during contact of the bovine claws with the ground have been documented by GRF and pressure measurements (Alsleben et al., 2003; van der Tol et al., 2003). High-speed cinematography was carried out for the first time in cattle by Herlin and Drevemo (1997) to evaluate various limb joint angles during locomotion. Using high-speed cinematography, the goal of the present study was to evaluate the ground contact patterns of the claws of heifers walking on a treadmill with specific reference to 1 ) order of claw contact with the treadmill surface, 2) initial claw contact area, and 3 ) effect of trimming on claw contact patterns.

\section{MATERIALS AND METHODS}

Eighteen Brown Swiss heifers with a mean age of $12.5 \mathrm{mo}(\mathrm{SD}=3 \mathrm{mo})$ and a $\mathrm{BW}$ of $382 \mathrm{~kg}(\mathrm{SD}=65 \mathrm{~kg})$ were used. Before entering the study, the heifers were kept on alpine pastures (13 animals) or in loose-housing systems (5 animals). They were clinically healthy, with no signs of lameness and no visible or palpable signs of claw horn disorders. They were acclimated to the treadmill and the experimental set-up in groups of 4 to 5 animals at a time. The training was conducted over $3 \mathrm{~d}$, and lasted 15 to $20 \mathrm{~min} / \mathrm{animal}$ each day. All 18 heifers were easily accustomed to the treadmill. Filming and gait analysis were started on $\mathrm{d} 4$ once the gait of the heifers on the treadmill had become regular and the animals were relaxed. The speed of the treadmill (Mustang 2200, Fa. Graber AG, Fahrwangen, Switzerland) could be adjusted in increments of $0.1 \mathrm{~m} / \mathrm{s}$ and was set individually until each animal achieved regular walking characteristics. On d 5, functional hoof trim- ming (Toussaint Raven, 1989) was carried out in the fore and hind limbs. Only minor trimming was required to correct slightly elongated dorsal and lateral walls and to level the larger lateral claws to the height of the medial claws. On d 6, filming and vertical GRF measurements were repeated. The heifers were returned to their owners on $d$ 7. According to animal welfare regulations of the Swiss Federal Veterinary Authorities, this study was assessed as having no adverse impact on animal welfare (level 0 ). The experiment was approved by the veterinary authorities of the canton of Zurich (Switzerland).

A digital high-speed camera (Motion Scope PCI 1000S, Redlake Imaging Corporation, San Diego, CA), with a frame rate of 500 pictures/s and a resolution of $320 \times 280$ pixels, connected to a personal computer was used. Three spotlights $(220 \mathrm{~V}, 1,000 \mathrm{~W}, 300 \mathrm{~Hz})$ were focused on the foot being studied. A film sequence lasting $4 \mathrm{~s}$ included 4 complete stride cycles. Considering the frame rate of 500 frames/s, this amounted to 2,000 frames per sequence. Each of the 4 limbs of an animal was filmed separately from 2 different views. Instead of simultaneous multiple cameras, subsequent film sequences were made from the different positions (Figure 1). A limb was filmed from one view in all animals of a group, and then the camera was repositioned for the next view or limb. The claws of the forelimbs, where the feet were placed on the ground in a plane sagittal to the shoulders, were filmed from the front and from the side but not from the back because they were blocked from view by the pelvic limbs. Likewise, the hind feet could not be filmed from behind because they usually touched the ground close to the median plane in front of the contralateral limb. Instead, the pattern of ground contact by the hind feet was filmed from the side and obliquely from the front at a $45^{\circ}$ angle representing the "frontal view" (Figure 1). The film sequences were visually assessed using a software program (MIDAS Player, Redlake Imaging Corp.). In the frontal views, the swing phase, the pattern of ground contact, and the widening of the interdigital space could be seen. In the side views, the subsequent ground contact of the different parts of the lateral and medial claws-heel, wall, and toe area-during the stance phase of the limb could be evaluated.

The vertical GRF were measured simultaneously in all 4 limbs using the instrumented treadmill (Weishaupt et al., 2002). For technical reasons, the vertical GRF measurements were determined in only 9 of the 18 heifers (Table 1). The system was not able to distinguish between the GRF of the lateral and medial claw. Forcetime histories were analyzed with software developed in-house (HP2, Equine Performance Center, University of Zurich), which allowed the automatic extraction of 


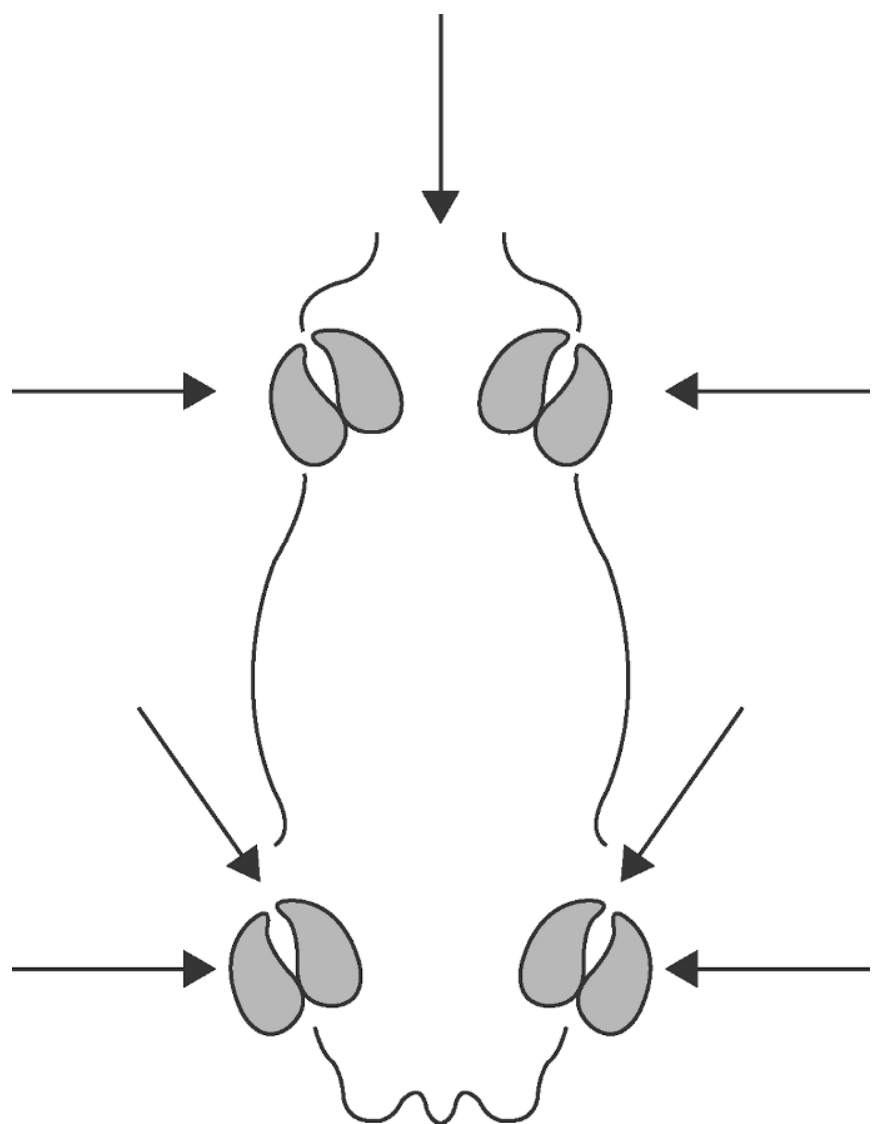

Figure 1. Camera positions for high-speed cinematography recordings. Because only one camera was available, subsequent movies of each position had to be made. The "frontal" view of the digits of the hind limbs was achieved from an oblique direction.

temporal and force variables for each limb separately. Extracted variables were stride frequency, stance duration, swing duration, and the peak vertical GRF. Ground reaction force data were sampled at $433 \mathrm{~Hz}$.

The statistical analysis of the data was done using StatView Version 5.0 (SAS Institute, Cary, NC). The data of the left and right front and of the left and right hind limbs were pooled and analyzed together. Means were compared using the paired $t$-test. The level of significance was set at $P<0.05$.

\section{RESULTS}

\section{Gait Analysis of the Forelimbs and Hind Limbs}

The speed of the treadmill was $1.40 \mathrm{~m} / \mathrm{s}(\mathrm{SD}=0.09$, range 1.25-1.54) before functional claw trimming and $1.33 \mathrm{~m} / \mathrm{s}(\mathrm{SD}=0.03$, range $1.27-1.35)$ after trimming. This difference was not statistically significant. The mean stride frequency was $55.0(\mathrm{SD}=2.7) \mathrm{min}^{-1}$ and remained the same after functional claw trimming. The stance duration as well as the swing duration did not differ between the forelimbs and hind limbs (Table 1). The peak vertical GRF was significantly higher in the forelimbs than the hind limbs. Functional claw trimming had no measurable effect on stance duration, swing duration, or peak vertical GRF (Table 1). Ground reaction curves were not different before and after claw trimming.

The digits of the forelimb were lifted and protracted with a slight inward rotation so that during the swing phase, they almost touched the contralateral fetlock. They contacted the ground with a slight outward rotation, which started to become apparent when the foot was still a few centimeters above the ground and the digits of the distal limb started to extend. In most forelimbs, the lateral claw contacted the ground before the medial claw (see below for details). At ground contact, the interdigital cleft pointed slightly outward. There was a marked passive widening of the interdigital cleft during which the medial claw was pushed medially, once the lateral claw had contacted the ground. The widening of the interdigital cleft remained unchanged throughout the rest of the stance phase. During the heel strike and maximum braking phases, pronounced oscillating movements along and perpendicular to the limb axis, of the claws and of the soft tissues of the foot, were observed.

The hind limbs were lifted with a slight inward rotation and protracted with a closed interdigital cleft. As in the forelimbs, active widening of the interdigital cleft and outward rotation of the claws were observed at ground contact. In almost all hind limbs, the lateral claw contacted the ground before the medial claw. The medial claw contacted the ground $0.014 \mathrm{~s}(\mathrm{SD}=0.012$; Figure 2a) after the lateral claw in the forelimbs and

Table 1. Temporal and force variables (standard deviation in parentheses) before and after functional claw trimming of the fore and hind limbs in 9 heifers

\begin{tabular}{|c|c|c|c|c|}
\hline Variable & $\begin{array}{l}\text { Forelimb before } \\
\text { claw trimming }\end{array}$ & $\begin{array}{l}\text { Forelimb after } \\
\text { claw trimming }\end{array}$ & $\begin{array}{l}\text { Hind limb before } \\
\text { claw trimming }\end{array}$ & $\begin{array}{l}\text { Hind limb after } \\
\text { claw trimming }\end{array}$ \\
\hline Stride frequency, $\min ^{-1}$ & 55.0 & 55.1 & 55.0 & 55.1 \\
\hline Stance duration, $\mathrm{s}$ & $0.70(0.03)$ & $0.68(0.09)$ & $0.69(0.26)$ & $0.66(0.87)$ \\
\hline Swing duration, s & $0.39(0.02)$ & $0.38(0.05)$ & $0.40(0.02)$ & $0.40(0.05)$ \\
\hline Peak vertical force, $\mathrm{N}$ & $947.9(26.5)$ & $918.5(58.6)$ & $769.7(26.6)$ & $753.6(38.4)$ \\
\hline
\end{tabular}




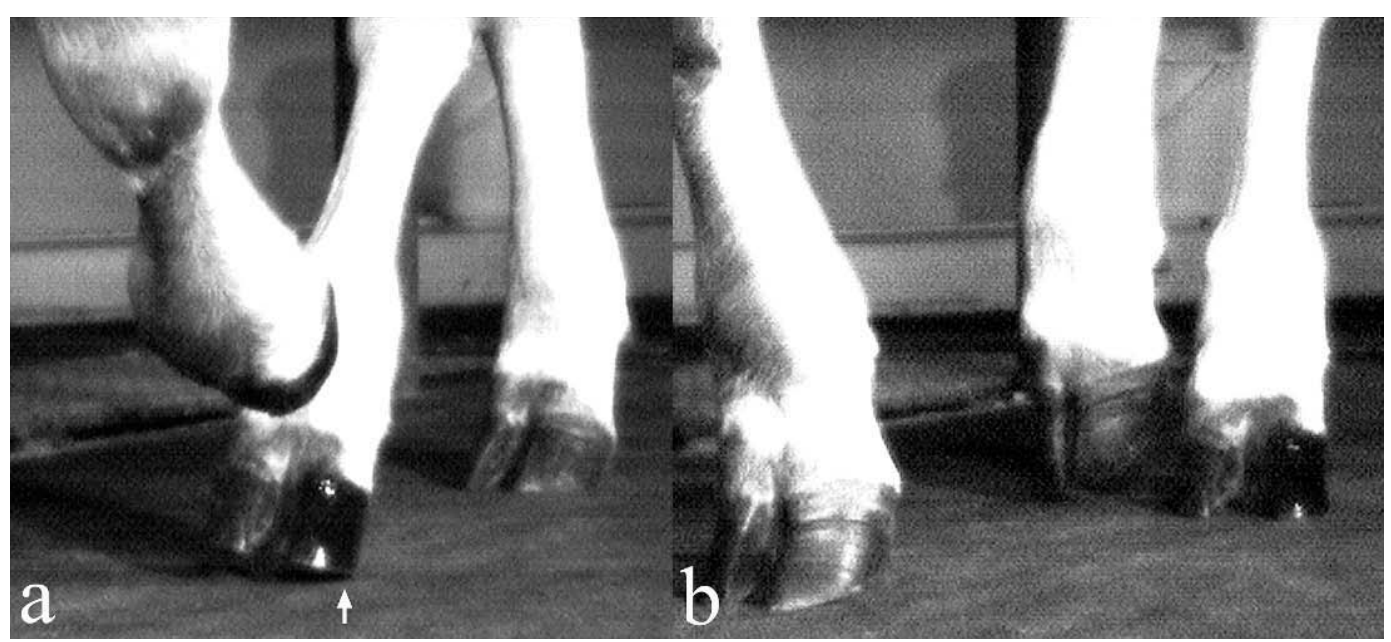

Figure 2. Ground contact of the claws of the left hind limb of a 15-mo-old Brown Swiss heifer walking on a treadmill, as viewed at a $45^{\circ}$ angle from the front of the animal. The foot contacts the ground in a tipping movement from the abaxial wall of the lateral claw to the medial claw. a) The heel of the lateral claw has contacted the ground (arrow) and the interdigital cleft faces slightly outward and begins to widen. b) The claws are in maximum contact with the ground during the midstance phase and the interdigital cleft is still at its maximum width.

$0.024 \mathrm{~s}(\mathrm{SD}=0.008)$ in the hind limbs. During the braking phase, the lateral claws slid only a few millimeters, if at all, on the rubber belt of the treadmill. There was no sliding of the medial claw. Active weight bearing by the medial claw became visibly apparent only during the transition to the midstance position (Figure $2 \mathrm{~b}$ ) and push-off phase.

In the forelimb and hind limb, the feet underwent a tipping movement from lateral to medial as they contacted the ground. This started as soon as the heel and abaxial border of the lateral claw contacted the ground and continued along the tip region of the lateral claw toward the medial claw.

\section{Ground Contact Before and After Functional Claw Trimming}

Before foot trimming, the lateral claw contacted the ground first in the majority of forelimbs (83\%). In the remainder of the forelimbs (17\%), the lateral and medial claws contacted the ground simultaneously. After functional claw trimming, there was an increase in the number of lateral claws (92\%) that contacted the ground first in the forelimbs; in the remaining $8 \%$, both claws contacted the ground simultaneously.

Before foot trimming, the lateral claw contacted the ground before the medial claw in all the hind limbs. After trimming, the lateral claw of the hind limbs contacted the ground first in almost all cases (97\%); in 1 case, both claws contacted the ground simultaneously.

\section{Claw Regions of Initial Ground Contact Before and After Functional Claw Trimming}

Before trimming, the heel of the lateral claw of forelimbs made initial contact with the ground in $47 \%$ and the abaxial wall of the lateral claw in another $47 \%$ of the limbs. In one heifer ( $6 \%$ of the limbs), the toe region of the lateral claw of both forelimbs contacted the ground first. After trimming, the heels of the lateral forelimb claws contacted the ground first in $64 \%$ of the limbs and the abaxial wall contacted the ground first in $36 \%$ of the limbs.

Before trimming, the heels of $50 \%$ of the lateral claws of the hind limbs contacted the ground first (Figure 3) and in $44 \%$ the abaxial wall made initial contact. In 1 heifer $(6 \%)$, the toes of the lateral claws of both hind limbs contacted the ground first. There was a marked change after trimming; the heel of the lateral claws became the region of initial contact with the ground in $78 \%$ of cases, and the abaxial wall became the region of initial contact in the remaining $22 \%$ of the hind feet.

In the medial claws of the forelimbs before trimming, the region of initial contact with the ground was the heel in $39 \%$, the abaxial wall in $42 \%$, and the toe in $19 \%$. After trimming, the heel of the medial claw made initial contact in 53\%, and contact with the abaxial wall occurred in $44 \%$ of the forelimbs; the toe contacted the ground first in 1 medial claw. In the medial claws of the hind limbs, the region of initial contact with the ground before trimming was the heel in $36 \%$ and the abaxial wall in $64 \%$. After trimming, the region of initial 


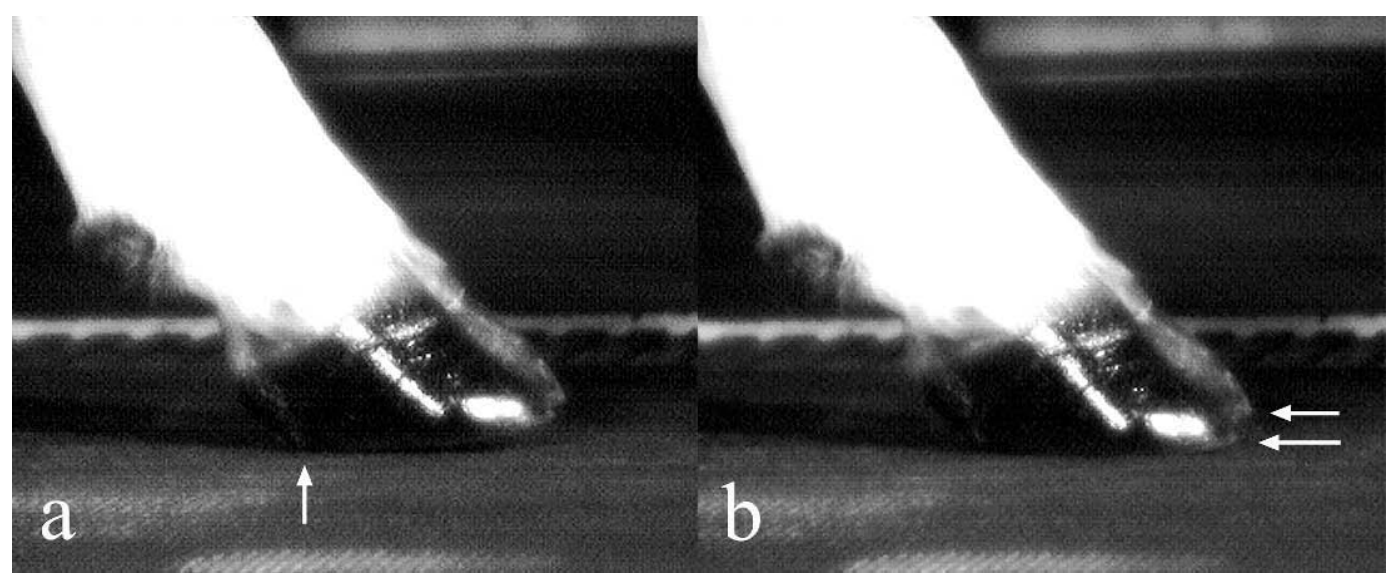

Figure 3. Ground contact of the claws of the right hind limb of a 15-mo-old Brown Swiss heifer walking on a treadmill, as viewed from the right side of the animal. a) The heel of the lateral claw (arrow) contacts the ground while its tip and the medial claw is still suspended. b) $6 \mathrm{~ms}$ later, the toe of the lateral claw contacts the ground while the toe of the medial claw is still suspended (arrows).

contact with the ground in the medial claws was the abaxial wall in $80 \%$ of the hind limbs. In the remaining $20 \%$, the region of initial contact was the heel.

\section{DISCUSSION}

Horses may require more than 1 wk of training to become accustomed to a treadmill (Buchner et al., 1994). The heifers of our study quickly adapted to the experimental settings. The speed of the treadmill was set individually to each heifer to obtain a regular, even gait in each animal. This was controlled by the regularity of the stride patterns and the GRF curves. There was no significant difference in the speed of the treadmill before $(1.40 \mathrm{~m} / \mathrm{s})$ or after $(1.33 \mathrm{~m} / \mathrm{s})$ claw trimming. The high-speed recordings showed that the lateral claw did slide a few millimeters, but once the medial claw contacted the ground, there was no further sliding. Because cattle claws are adapted to walk on soft surfaces, the rubber belt of a treadmill might reflect a more natural surface than concrete and therefore the gait might be more natural. Similarly, van der Tol et al. (2003) covered the measuring apparatus and pathway with a 5 - to $6-\mathrm{mm}$ rubber mat to provide adequate footing and prevent postural adjustments due to slipping. The gait of horses on a treadmill, however, is specific and shows some differences compared with other surfaces (Buchner et al., 1994). To our knowledge, there are no published reports that specifically compare ground contact patterns of cattle on a treadmill with those on other surfaces. The gait pattern on the treadmill did not differ between heifers previously kept on alpine pastures or in loose-housing systems, which suggests that these patterns are inborn and inherent.
High-speed cinematography allowed a detailed visual assessment of the different phases of a stride cycle. The way in which the forelimb was advanced in the terminal part of the swing phase corresponds to its anatomical properties. The extensor tendons, running dorsolaterally, and the anatomical shape of the distal aspect of the radius (Schraml, 1925) result in outward rotation of the claws as they contact the ground. The outward rotation of the digits immediately before ground contact was also observed in the hind limbs. Immediately before landing, the claws spread slightly apart but, in contrast to the results of another study (Fessl, 1974), the widening of the interdigital cleft occurred mainly after the lateral claw had contacted the ground. The medial claw then briefly moved away from the lateral claw before it contacted the ground in a sudden movement. This sequence gave the impression that the lateral claw was placed on the treadmill surface consciously and the medial claw in an involuntary fashion. The marked widening of the interdigital cleft may lead to irritation of the interdigital skin and subsequent interdigital hyperplasia. The passive widening of the interdigital cleft did not progress any further during the midstance and propulsion phases.

It was clearly evident that the lateral claw contacted the ground before the medial claw in both the forelimbs and hind limbs. The time difference in ground contact between the lateral and the medial claw was less in the front limbs $(0.014 \mathrm{~s})$ compared with the hind limbs $(0.024 \mathrm{~s})$. Thus, the lateral claw in cattle received the majority of the initial GRF at heel strike and during maximum braking. With respect to the hind limb, but not the forelimb, these findings are in agreement with those of van der Tol et al. (2003). Possibly, the subtle 
differences between the ground contact of the claws in the forelimbs could not be detected in the latter study because the measuring frequency was $250 \mathrm{~Hz}$ compared with $500 \mathrm{~Hz}$. In addition, because the feet were placed on the ground in a plane sagittal to the shoulders, the vertical GRF may be distributed more evenly between the front claws during the entire stance phase. Also, the musculotendinous attachment of the forelimbs to the trunk may influence GRF. However, in support of our findings, Carvalho et al. (2005) found that in 32 Holstein cows, the peak pressures in the braking and deceleration phases were concentrated on the lateral sole and heel for all 4 limbs.

On hard surfaces such as slatted concrete floors, the lateral claw is considerably more stressed than the medial claw, especially in the hind limbs. van der Tol et al. (2003) reported that about $75 \%$ of the vertical GRF was exerted on the lateral hind claws of dairy cows at a walk. In addition, on hard surfaces, frictional forces on the soft horn of the heel could be detrimental for the lateral claw (van der Tol et al., 2003). The observed ground contact pattern may help to explain why the lateral claws of the hind limbs are predisposed to sole ulcers and more severe laminitic changes. Also, interdigital hyperplasia, which is usually more pronounced in the lateral part of the interdigital space, may result from contusion of the soft tissue caused by the upward pressure of the axial wall of the lateral claw.

Using a frequency of 500 frames/s, it was evident that the medial claw contacted the ground after the lateral claw and seemed to sustain a lesser load during the transition to the midstance position. The weight distribution between the lateral and medial claws could not be differentiated by force plate measurements in our study. The physiological purpose of greater loading of the lateral claw compared with the medial is not known. On soft surfaces such as grass, this may have little impact on the lateral claw because it can sink into the ground, followed by the medial claw. In doing this, it may contribute to the static and dynamic stabilization of the center of gravity of the animal while standing, walking, or running. Likewise, trotting horses showed a fixed hoof-unrollment pattern, and hoof trimming did not have much influence on the way of landing. In these horses, lateral landing was regarded as the physiological standard (van Heel et al., 2004). Lateral asymmetric landing might also be regarded as standard in walking cattle.

A number of researchers have measured the forces acting upon the claws of the forelimbs and hind limbs of standing cattle and reported that the medial claw of the forelimb receives more weight load than the lateral claw (van der Tol et al., 2002, 2003; Alsleben et al., 2003; Huth et al., 2005). This indicates that the pressure distribution in standing and walking cattle may be different. Age also plays a role with overload of the lateral claw of the hind limbs being more obvious in older animals (Alsleben et al., 2003; Huth et al., 2005). The position of the limbs during the pressure measurement, however, is also important. The exact position of the limbs was not defined in the studies by Alsleben et al. (2003) and van der Tol et al. (2003) and the level of foot care was described only by the latter authors. Most likely, standing animals assume a position during pressure measurements in which load distribution is as even as possible between the claws of a foot. When the hind limbs of animals were manually forced into a position perpendicular to the ground, the forces acting on the lateral claws were considerably greater than those acting on the medial claws (Kehler and Gerwing, 2004).

It was clearly evident from our cinematographic analysis of the walk on the treadmill that in the forelimb, as in the hind limb, the outside claw generally touched the ground before the medial claw. A difference in the length of the medial and lateral digits may contribute to this (Nuss and Paulus, 2006). Nacambo et al. (2004) found that in the metacarpal and metatarsal bones of calves and cows, the lateral condyle of the metacarpal and metatarsal bone was slightly longer than the medial, and Schwarzmann (2004) showed that the difference in length was increased to the pedal joint. This anatomical difference was smaller in the front limbs and greater and regularly present in the hind limbs. It is not clear whether an anatomical difference alone could explain the greater relative weight bearing by the lateral claws. We suspect that another contributing factor is the gait pattern in which the hind foot contacts the ground close to the median.

Claw trimming had no effect on which claw contacted the treadmill surface first. However, it did increase the frequency with which the heel of the lateral claw became the region of initial contact with the ground (50 vs. 78\%), presumably because the dorsal wall had been cut to the normal length. Therefore, with regard to gait patterns, our observations indicate that claw trimming mainly affects the area of first contact of the claws. Furthermore, gait patterns are not easily changed but remain fairly uniform after trimming. This may explain why the effects of preventive claw trimming are only slight and short-lived (Kehler and Gerwing, 2004). Claw trimming cannot be the only answer to claw health problems in cattle kept on concrete floors. However, claw trimming reduces points of maximal pressure in the lateral claws to some extent and aids in redistributing the pressure to the medial claws (Alsleben et al., 2003; Kehler and Gerwing, 2004; van der Tol et al., 2004; Carvalho et al., 2005). Because the effect is rela- 
tively short-lived, more frequent claw trimming, possibly 3 to 4 times a year, may be necessary to achieve and maintain optimal claw health.

In conclusion, the results of the present study showed that the heel of the lateral claws, especially at the hind limbs, was the region that sustained the impact force at heel strike and maximum braking. The landing of the bovine foot at the walk on a treadmill can be described as a tipping movement, which starts at the heel of the lateral claw and progresses from the abaxial and axial walls of the lateral claw toward the medial claw. "Heel first" lateral asymmetric landing may be the normal gait pattern in cattle at the walk, which therefore may lead to overload and disease of the lateral claw on hard surfaces.

\section{REFERENCES}

Alsleben, B., A. Russke, J. Werde, H. Hamann, and O. Distl. 2003. Messung der Druckverteilung unter den Klauen bei Rindern der Rasse Deutsche Holsteins in den ersten zwei Lebensjahren. Prakt. Tierarzt. 84:232-240.

Buchner, H. H., H. H. Savelberg, H. C. Schamhardt, H. W. Merkens, and A. Barneveld. 1994. Kinematics of treadmill versus overground locomotion in horses. Vet. Q. 16(Suppl. 2):S87-S90.

Carvalho, V., R. Bucklin, J. Shearer, and L. Shearer. 2005. Effects of trimming on dairy cattle hoof weight bearing and pressure distributions during the stance phase. Trans. ASAE 48:16531659 .

Collick, D. W., W. R. Ward, and H. Dobson. 1989. Associations between types of lameness and fertility. Vet. Rec. 125(5):103-106.

Fessl, L. 1974. Die Gelenkaktionen des Rindes im Schritt. Ein Beitrag zur Bewegungsanalyse des Rindes. Dtsch. Tierarztl. Wochenschr. 81:129-132.

Herlin, A. H., and S. Drevemo. 1997. Investigating locomotion of dairy cows by use of high speed cinematography. Equine Vet. J. Suppl. 23:106-109.

Huth, C., A. Russke, B. Alsleben, H. Hamann, and O. Distl. 2005. Body and claw measurements and pressure distribution under the claws in heifers of different cattle breeds. Berl. Munch. Tierarztl. Wochenschr. 118(3-4):150-159.

Kehler, W., and T. Gerwing. 2004. Effects of functional claw trimming on pressure distribution under hind claws of German Holstein cows. Pages 103-104 in Proc. 13th Int. Symp. 5th Conf. Lameness in Ruminants, Maribor, Slovenija. B. Zemljic, ed. Zemljic and Co., Maribor, Slovenia.
Leach, D. 1993. Recommended terminology for researchers in locomotion and biomechanics of quadrupedal animals. Acta Anat. (Basel) 146(2-3):130-136.

Nacambo, S., M. Hässig, C. Lischer, and K. Nuss. 2004. Differences in length of the metacarpal and metatarsal condyles in calves and the correlation to claw size. Proc. 13th Int. Symp. 5th Conf. Lameness in Ruminants, Maribor, Slovenija. B. Zemljic, ed. Zemljic and Co., Maribor, Slovenia.

Nuss, K., S. Gantke, R. G. Köstlin, and U. Fuhrmann. 1996. Radiology of laminitis in cattle. Page 126 in Proc. 19th World Buiatrics Congress, Edinburgh, UK. BCVA, Edinburgh, UK.

Nuss, K., and N. Paulus. 2006. Measurements of claw dimensions in cows before and after functional trimming: A post-mortem study. Vet. J. 172:284-292.

Phillips, C. J., P. C. Chiy, M. J. Bucktrout, S. M. Collins, C. J. Gasson, A. C. Jenkins, and M. J. Paranhos da Costa. 2000. Frictional properties of cattle hooves and their conformation after trimming. Vet. Rec. 146:607-609.

Schraml, O. 1925. Untersuchungen am Karpalgelenk des Rindes. Inaugural-Dissertation, Ludwig-Maximilians-Universität, München, Germany.

Schwarzmann, B. 2004. Untersuchungen der Klauengrössen und der Zehenlänge bei Kälbern - klinische und röntgenologische Befunde. Inaugural-Dissertation, Ludwig-Maximilians-Universität, München, Germany.

Smits, M., K. Frankena, J. Metz, and J. Noordhuizen. 1992. Prevalence of digital disorders in zero-grazing cows. Livest. Prod. Sci. 32:231-244.

Toussaint Raven, E. 1989. Cattle footcare and claw trimming. 3rd ed. Farming Press, Ipswich, UK.

van der Tol, P. P. J., J. H. M. Metz, E. N. Noordhuizen-Stassen, W. Back, C. R. Braam, and W. A. Weijs. 2002. The pressure distribution under the bovine claw during square standing on a flat substrate. J. Dairy Sci. 85:1476-1481.

van der Tol, P. P. J., J. H. M. Metz, E. N. Noordhuizen-Stassen, W. Back, C. R. Braam, and W. A. Weijs. 2003. The vertical ground reaction force and the pressure distribution on the claws of dairy cows while walking on a flat substrate. J. Dairy Sci. 86:2875-2883.

van der Tol, P. P., S. S. van der Beek, J. H. Metz, E. N. NoordhuizenStassen, W. Back, C. R. Braam, and W. A. Weijs. 2004. The effect of preventive trimming on weight bearing and force balance on the claws of dairy cattle. J. Dairy Sci. 87:1732-1738.

van Heel, M. C., A. Barneveld, P. R. van Weeren, and W. Back. 2004 Dynamic pressure measurements for the detailed study of hoof balance: The effect of trimming. Equine Vet. J. 36:778-782.

van Ingen-Schenau, G. 1980. Some fundamental aspects of the biomechanics of overground versus treadmill locomotion. Med. Sci. Sports Exerc. 12:257-261.

Weishaupt, M. A., H. P. Hogg, T. Wiestner, J. Denoth, E. Stussi, and J. A. Auer. 2002. Instrumented treadmill for measuring vertical ground reaction forces in horses. Am. J. Vet. Res. 63:520-527. 